\title{
Synthesis and Characterization of Anionic Long Chain Fatty Alkyl Salicylate Based on Juagafa Seed Fat and Grape Seed Oil
}

\author{
W.I.A. El-Dougdoug ${ }^{\text {a.b }}$ and K. A. H. Hebash ${ }^{\text {a }}$ \\ ${ }^{a}$ Chemistry Department, Faculty of Science, Benha University, \\ Benha, Egypt and ${ }^{b}$ Chemistry Department, Universal College, \\ Makkah El-Mukarramah, Saudi Arabia.
}

\begin{abstract}
A SERIES of anionic surface active agents were prepared from salicylic acid by esterification with fatty alcohols (Ia-i) [decyl C10: 0, dodecyl C1: 0, tetradeyl C14 : 0, hexadecyl C16 : 0, octdecyl C18 : 0, octdec 9-enyl C18:1, octdec 9,12-dienyl C18:2, mixed fatty alcohol of Juagafa seed fat and mixed fatty alcohols of Grape oil ], in the presence of $p$-toluene sulfonic acid as catalyst , forming an alkyl salicylates [IIa-i], which are converted to anionic sulfated, sulfonated fatty alkyl salicylate [IVa-i). Also, the prepared esters (IIa-i) were oxypropylated with various unit of propylene oxide (2, 4 and 6 moles) to give (IIIa-i). These compounds were converted to a modified anionic surfactants (Va-i) as molecular aggregations and surface active agents in aqueous media. These derivatives were purified and characterized by micro-analysis, IR and ${ }^{1} \mathrm{H}-\mathrm{NMR}$ spectra studies. Also, surface activity, and biodegradability were evaluated. The improved synthesized anionic surface active agents with propylene oxide, from commercial grape oil and or juagafa fat revealed good surface activities such as surface and interfacial tension, lower $\mathrm{T}_{\text {K.p }}$, high foam height, good tolerance toward hard water, higher stability towards basic media and high biodegradable compounds. This situation focused our attention to utilize an economic low priced sources for preparation of surface active compounds with high important applications in industrial field and decease the environmental pollution .
\end{abstract}

Keywords: Utilization of industrial wastes (Juagafa seed fat, Grape seed oil), Esterfiction, Surface active properties and Biodegradability.

The term surfactant is a blend of "Surface Active Agent". Surfactants are usually amphiphilic organic compounds (normally possessing a hydrophobic tail and a hydrophilic head), which allows them to change the interfacial properties of liquids in which they are present. Surfactants are commonly classified into four categories, according to the formal charge present in their hydrophilic head: 
anionic (negatively charged), cationic (positively charged), nonionic (uncharged) and amphoteric (presents both positive and negative charges at an intermediate $\mathrm{pH})$. For each classification, it is possible to sub-classify according to the functional group of the hydrophilic head. For the household industry, the most common anionic surfactants are those with a sulfate, sulfonate, or carboxylate (soap) group attached to them. The most important synthetic anionic surfactant in volume today are alkyl benzene sulfonates (ABS), followed by the ethoxylated alkyl sulfates (AES) and alkyl sulfate (AS). They are found mainly in detergents, householed and industrial cleaning products and also, for the latter two, in cosmetics and pharmaceuticals, especially in personal formulations such as shampoos ${ }^{(1-3)}$. The surface active agents derived from natural sources acquired more value and interest from two points of view economic (has low price) and environmental pollution (reduced pollution). Our interest was extended to prepare the surface active agents from rubbish sources like fatty acids extracted from Mangifera indica ${ }^{(4)}$, Rice bran oil ${ }^{(5,6)}$ and Gawafa seeds ${ }^{(7)}$. The alkaline catalyzed reactions of fatty alkyl salicylate esters with PO and composition of their reaction products were studied, moreover, surface active properties as detergents and surface active agents of their sulfated products were evaluated ${ }^{(7)}$. The addition of propylene oxide unit to the hydrophobic part has advantage effect, enhanced the hydrophobic moiety of surfactant or modifying their surface active properties ${ }^{(8,9)}$. The solubility of hydroxypropylated products is very poor and can be improved by sulfation ${ }^{(7)}$. In the present investigation a family of a series of hydroxypropylated fatty alkyl salicylate from fatty alcohols $(\mathrm{I})_{\mathrm{a}-\mathrm{h}}$, of [octyl $\mathrm{C}_{8}$, decyl $\mathrm{C}_{10}$, dodecyl $\mathrm{C}_{12}$, tetradecyl $\mathrm{C}_{14}$, hexadecyl $\mathrm{C}_{16}$, octadecyl $\mathrm{C}_{18}$, octadec 9-enyl $\mathrm{C}_{18: 1}$ and mixed fatty alcohols of Jauafa Seed Fat (JSF)] were prepared, by hydroxypropylation in the presence of catalysts ( $\mathrm{KOH}$ at $120-130^{\circ} \mathrm{C}$ ), respectively, followed by sulfation and neutralization to produce sulfated oxypropylated alkyl salicylate as anionic surfactant.

\section{Material and Methods}

All the melting points are uncorrected. The IR spectrum was measured by Pye-Unicam SR-1000 infra-red Spectrophotometer as KBr disk or nujl mull and ${ }^{1} \mathrm{H}-\mathrm{NMR}$ was done in DMSO as solvent and tetramethylsilane (TMS) as internal standard [Varian EM-390] Spectrophotometer operating at $260 \mathrm{MHz}$.

Industrial wastes of Jauafa seeds and Grape seeds, were kindly supplied by El-Nasr Company of canned products, Kaha, and Grape seeds from Aga juices company Egypt. The oil was extracted from the seeds. The specifications are given in Table 1.

Egypt. J. Chem. 54, No.2 (2011) 
Synthesis and Characterization of Anionic Long Chain Fatty Alkyl Salicylate... 259

a)

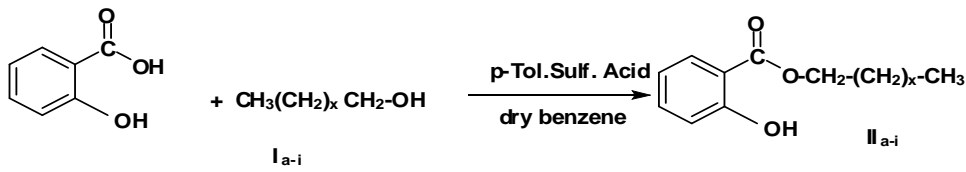

$x=8,10,12,14,16,16: 1,16: 2$, mixed alcohol of Juagafa Fat and mixed alkyl of grape oil

b)

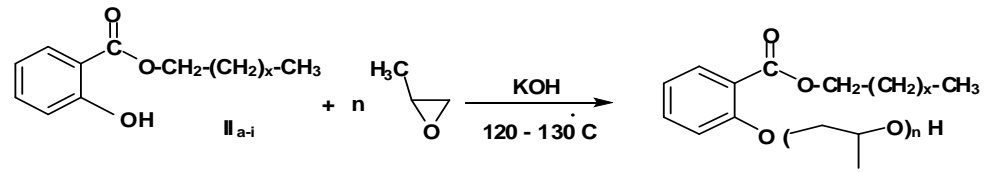
i) $\mathrm{ClSO}_{3} \mathrm{H} / \mathrm{CCl}_{4}$ ii) $\mathrm{NaOH}$ $n=2,4,6$ mole propylene oxide add

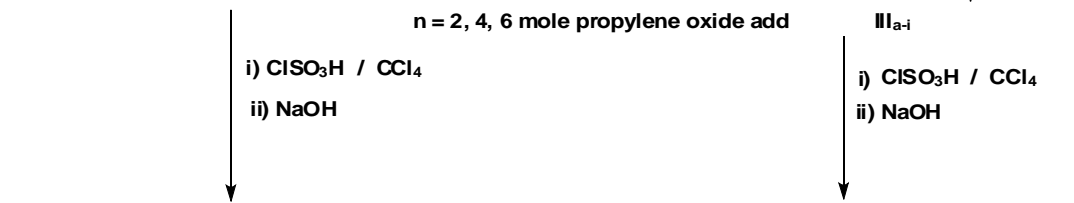<smiles>CCCOC(=O)c1cc(S(=O)(=O)[O-])ccc1OS(=O)(=O)[O-]</smiles><smiles>CCCOc1ccc([N+](=O)[O-])cc1C(=O)OCCCC(C)OS(=O)(=O)[O-]</smiles>

$\mathbf{N}_{\mathbf{a}-\mathbf{i}}$

(Va-i ) 2,4 and 6

Scheme 1

Hydrolysis of crude Jauafa seeds fat and or Grape seed oil

The procedure described by El-Sawy et al. ${ }^{(10)}$ was followed. The fatty acids mixture was analyzed by G. L. C. and their compositions are given in Table 1.

TABLE 1. Fatty acids composition and chemical characteristic of Juagafa Fat and Grape oil $^{(10)}$.

\begin{tabular}{|c|c|c|}
\hline \multirow[t]{2}{*}{ Chemical Characteristics } & \multicolumn{2}{|c|}{$\begin{array}{c}\text { Fatty acid composition } \\
\text { Peak area } \%\end{array}$} \\
\hline & Juagafa fat & Grape oil \\
\hline Gawafa fat: & Saturated fatty acids: & Saturated fatty acids: \\
\hline$=25.5$ & $\begin{array}{lll}\text { Caprylic acid } & \mathrm{C}_{8: 0} & 12.51\end{array}$ & $\overline{\text { Lauric acid } \quad \mathrm{C}_{12: 0}} 00.61$ \\
\hline$=11.8$ & $\mathrm{C}_{10: 0} \quad 01.94$ & Myristic acid $\quad C_{14: 0} \quad 00.30$ \\
\hline$=197.8$ & $\mathrm{C}_{12: 0} 26.61$ & Palmitic acid $\mathrm{C}_{16: 0} \quad 10.23$ \\
\hline$=2.03$ & Myristic acid & Stearic acid $\quad \mathrm{C}_{18: 0} \quad 06.42$ \\
\hline Grape Oil:- & Palmitic acid & \\
\hline$\overline{\text { A.V. }}=3.34$ & Stearic acid $\quad \mathrm{C}_{18: 0} 31.00$ & Unsaturated Fatty acids: \\
\hline$=132.8$ & Unsaturated Fatty acids: & Palmitoleic acid $\mathrm{C}_{16: 1} 3.10$ \\
\hline$=187.6$ & $\mathrm{C}_{18: 1} \quad 04.44$ & $\mathrm{C}_{18: 1} 17.24$ \\
\hline$=2.83$ & & Linoleic acid \\
\hline
\end{tabular}


Reduction of oil to corresponding fatty alcohols

Fatty alcohols of Juagafa fat and or grape oil were prepared by reduction of the corresponding mixed methyl esters using lithium aluminum hydride $(\mathrm{LAH})^{(11)}$. Pure mixed fatty alcohols were obtained from the above prepared products by saponification to remove the unreacted fatty ester, followed by extraction (c.f. Table 2).

Fatty alkyl salicylate

Salicylic acid was esterified with fatty alcohols $(\mathrm{I})_{\mathrm{a}-\mathrm{i}}$, of [decyl $\mathrm{C}_{10}$, dodecyl $\mathrm{C}_{12}$, tetradecyl $\mathrm{C}_{14}$, hexadecyl $\mathrm{C}_{16}$, octadecyl $\mathrm{C}_{18}$, octadec 9-enyl $\mathrm{C}_{18: 1}$, octa 9 , 12-dienyl mixed fatty alcohols of Jauafa Fat (JSF)] and/ or Grape oil fatty alcohols, using Dean Stark adapter in dry benzene as solvent and p-toluene sulfonic acid as catalyst to afford fatty alkyl salicylate esters (II) $)_{\mathrm{a}-\mathrm{i}}{ }^{(12)}$.

Sulfated oxypropenoxylation of fatty alkyl salicylate $(\text { II })_{a-h}$.

The procedure described by El-Sawy et $a l^{(10)}$, was followed with a modification in which, interaction of fatty alkyl salicylate (II) a-i $_{\text {i }}$, propylene oxide and $\mathrm{KOH}$ as catalyst was conducted at $120-130{ }^{\circ} \mathrm{C}$ for about $6 \mathrm{hr}$.

\section{Evaluation method of surface active properties}

Surface and interfacial tension measurements

Surface and interfacial tension measurements of the prepared surfactants were made at room temperature $\left(25^{\circ} \mathrm{C}\right)$ with a Du Nouy tensiometer (DST 30 Series) using distilled water solution of $0.1 \%$ weight concentration ${ }^{(13)}$. The surface tension of the used distilled water was $73 \mathrm{mN} / \mathrm{m}$ and the interfacial tension between medicinal paraffin oil and distilled water was $56.2 \mathrm{mN} / \mathrm{m}$. Surfactant solutions were aged for $1 / 2 \mathrm{hr}$ before any measurements were made. Three readings were made on each sample to determine any change with time and to obtain an average value ${ }^{(9)}$.

TABLE 2 . Reduction of methyl esters of Juagafa Fat and Grape oil by $\mathrm{LiAlH}_{4}$ to fatty alcohol.

\begin{tabular}{|c|c|c|c|c|c|c|c|}
\hline \multirow{2}{*}{ Fatty Sample } & \multicolumn{2}{|c|}{$\begin{array}{c}\text { Saponification } \\
\text { value }\end{array}$} & \multicolumn{2}{|c|}{ Hydroxyl value } & \multicolumn{2}{|c|}{ Iodine Value } & \multirow{2}{*}{$\begin{array}{l}\text { Red. } \\
\text { Yield } \\
\text { a \% }\end{array}$} \\
\hline & Ester & $\begin{array}{l}\text { Red. } \\
\text { Prod. }\end{array}$ & Ester & $\begin{array}{l}\text { Red. } \\
\text { Prod. }\end{array}$ & Ester & $\begin{array}{l}\text { Red. } \\
\text { Prod. }\end{array}$ & \\
\hline $\begin{array}{c}\text { Mixed fatty } \\
\text { methyl ester } \\
\text { of Juagafa } \\
\text { Seed Fat }\left(I_{h}\right)\end{array}$ & 199.5 & 37.50 & - & 199.0 & 11.9 & 11.6 & 81.20 \\
\hline $\begin{array}{c}\text { Mixed fatty } \\
\text { methyl ester } \\
\text { of grape } \\
\text { oil }\left(I_{i}\right)\end{array}$ & 187.6 & 35.72 & - & 193.8 & 132.8 & 131.7 & 80.95 \\
\hline
\end{tabular}

$\mathrm{a}=(\mathrm{S}$. V. of ester $-\mathrm{S}$. V. of reduced product $) / \mathrm{S}$. V. of ester $\mathrm{x} 100$.

Egypt. J. Chem. 54, No.2 (2011) 


\section{Kraft point}

was measured as the temperature at which $1 \%$ dispersion solution becomes clear on gradual heating ${ }^{(14)}$.

\section{Wetting time}

This was determined by immersing a sample of cotton fabric in $0.1 \%$ aqueous solution of the surfactants ${ }^{(15)}$.

\section{Foaming properties}

These were measured according to Ross Miles method ${ }^{(16)}$. The foam production for $1.0 \%$ solution was measured by the foam height initially produced.

\section{Emulsification stability}

Emulsifying time, was determined according to a previously described $\operatorname{method}^{(17)}$. Surfactant solution $(0.1 \mathrm{~g} / 10 \mathrm{ml})$ and paraffin oil $(10 \mathrm{ml})$ were mixed in a measuring cylinder and after vigorous shaking (10 times), the tube was allowed to stand till any separation of the two phases appeared.

Stability to hydrolysis

A mixture of $10 \mathrm{~m} . \mathrm{mol}$. polymeric surfactant and $10 \mathrm{ml} .0 .05 \mathrm{~N} \mathrm{NaOH}$ were placed in a thermostat at $40^{\circ} \mathrm{C}$. The time required for a sample solution to be clouded as a result of hydrolysis shows the stability of surfactant to hydrolysis ${ }^{(18)}$.

$\mathrm{Ca}^{2+}$ stability was determined by a modified Hart method. Where, the surfactant $(10 \mathrm{~m} . \mathrm{mol})$ solution was titrated against $\mathrm{CaCl}_{2}(0.1 \mathrm{~N})$ solution. The end point was determined by visual observed of cloudiness the surfactant solution $^{(19)}$.

\section{Determination of the critical micelle concentration}

The CMC of the prepared surfactant was determined by the surface tension method. In these methods, values of the surface tension obtained for various concentrations of aqueous solutions of the prepared surfactants were plotted versus the corresponding concentrations ${ }^{(13,20,21)}$.

\section{Biodegradability \%}

Biodegradability percentage was determined following the method of Eter et al $^{(22)}$, according to the following equation:

where: $\quad \gamma_{\mathrm{t}}=$ Surface tension at time $\mathrm{t}$.

$$
\mathrm{D} \%=\left[\gamma_{\mathrm{t}}-\gamma_{0} / \gamma_{\mathrm{bt}}-\gamma_{0}\right] \times 100
$$

$\gamma_{0}=$ Surface tension at time zero.

$\gamma_{\mathrm{bt}}=$ Surface tension of blank at time $t$, without sample. 


\section{Results and Discussion}

The preparation of anionic surfactants $[\mathrm{IV}]_{\mathrm{a}-\mathrm{i}}$ and the improved oxypropylated Sulfo- alkyl salicylate $\left[\mathrm{V}_{\mathrm{a}-\mathrm{i}}\right]_{2,4}$ and 6 was performed according to the preparation methodology giving suitable yields. Micro-analysis of starting material; Infrared (IR) and Proton Nuclear Magnetic Resonance ( $\left.{ }^{1} \mathrm{H}-\mathrm{NMR}\right)$ spectra; were carried out to confirm the structure of some examples of the prepared compounds (Tables 3 ).

\section{Surface properties}

Surface and interfacial tensions

The measured values of surface and interfacial tensions of the prepared surfactants are given in Tables 4-5. The surface and interfacial tensions values increase with increases the number of carbon atom in alkyl chain ${ }^{(20)}$. On other hand, the presence of propylene oxide cooperating with sulfate/sulfonate groups improve the surface and interfacial tensions ${ }^{(23)}$.

\section{Kraft point}

The Kraft temperature (also known as Kraft point, or critical micelle temperature) is the minimum temperature at which surfactants form micelles. Below the Kraft temperature. Table 4-5, showed that, surfactants with propylene oxide with sulfogroup increases the solubility of the molecule. These compounds satisfy lower values of Kraft point $\left(\mathrm{T}_{\mathrm{Kp}}\right)$ more than that other prepared anionic surfactants, where, $\mathrm{T}_{\mathrm{KP}}$ increases with increases the hydrophobicity of the molecule This, might lead to a wide uses in industrial applications ${ }^{(24-25)}$.

\section{Wetting time}

The wetting properties of surfactant is one of its most important surface properties. For example, in laundry cleaning or textile processing, the wetting of surfactants may accelerate the diffusion or penetration of alkali chemicals and dyes into fibers and improve the detergency or dyeing effects. From data recorded in (Table 4-5), it was found that, a low p.o content has the most efficient wetting promoter, and it increases as the alkyl chain length increases ${ }^{(20)}$.

\section{Foaming height}

The foam height of the prepared surfactants decrease with increasing propylene oxide. From data recorded, anionic sulfo-alkyl salicylate from Gawafa fat and grape oil reveal higher foam than all prepared compounds. On other hand, IVa-i, have higher foam height than other prepared oxypropylated sulfo-alkyl salicylate derivatives ${ }^{(23)}$.

\section{Emulsification stability}

It was reported that, lower emulsifying properties were obtained with all anionic derivatives especially without the presence of propylene oxide. From the data given in Table 4-5, emulsification stability increased with the number of methylene group in its molecule means that the oxypropylated alkyl salicylate of Juagafa fat and Grape oil posses greater emulsifying stability than that of the other prepared compounds.

Egypt. J. Chem. 54, No.2 (2011) 
Synthesis and Characterization of Anionic Long Chain Fatty Alkyl Salicylate... 263

Egypt. J. Chem. 54, No.2 (2011) 
Egypt. J. Chem. 54, No.2 (2011) 
Synthesis and Characterization of Anionic Long Chain Fatty Alkyl Salicylate... 265

Egypt. J. Chem. 54, No.2 (2011) 
Stability to hydrolysis

From the data recorded in Table 4-5, the stability of the synthesized surfactants increases with. It can be seen that all the prepared compound have higher stability in basic medium, this may be due the presence of sulfo-group operating with propylene oxide ${ }^{(25)}$.

\section{$\mathrm{Ca}^{2+}$ stability}

From data showed in Tables 4-5, It is found that, oxypropylated alkyl salicylates (Va-i)2,4 and 6 showed higher stability to $\mathrm{Ca}^{+2}$ than that, of sulfoalkyl salicylate IVa-i, where as the oxypropylated alkyl salicylate tolerates the hard water more than the sulfo-alkyl salicylate. $\mathrm{Ca}^{+2}$ stability increases by increasing the number of $\mathrm{P}$. O unit in the surfactant ${ }^{(18)}$. Also, anionic prepared from Juagafa fat and Grape oil recorded higher tolerance towards hard water similar that, prepared from pure fatty alcohols.

\section{Critical micelle concentration}

The cmc of the synthesized surfactant were determined by the surface tension method $^{(13,20-21)}$, from data showed in Tables 4-5, it can be seen that; the values of cmc increase with increases the number of P.O. adducts and number of carbon atom in alkyl chain ${ }^{(27)}$.

\section{Biodegradability}

Biodegradability is deterred and degradation is slowed as steric hindrance increases $^{(28)}$. The results of biodegradability of IVi, IVh, Vi6, and/or Vb2, reflect the fact that, it decreases with increasing the number of repeating units of propenoxy groups as well as, the repeating alkyl groups in hydrophobic unit ${ }^{(29)}$ as shown in Fig. 1.

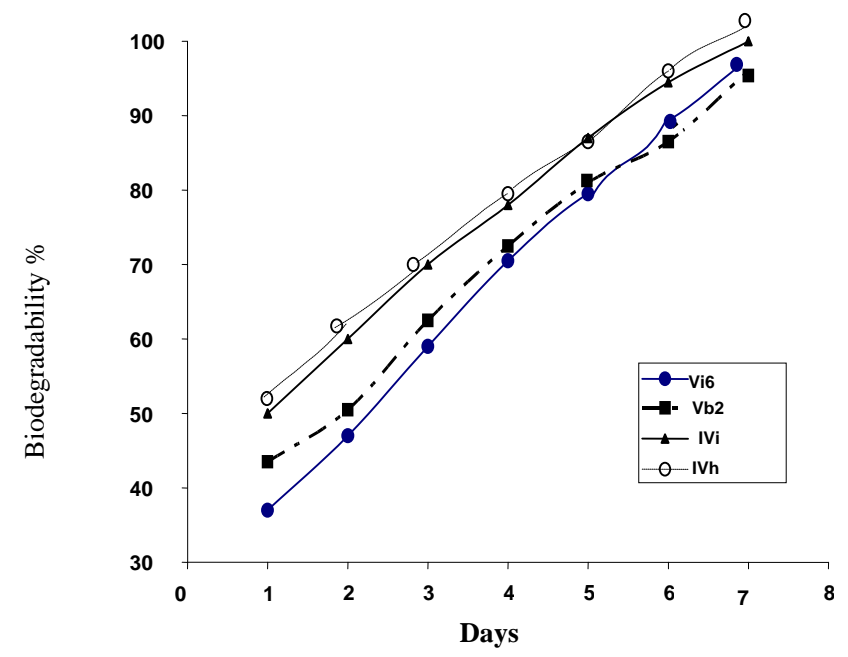

Fig. 1. Biodegradability \% of Sulfated / Sulfonated alkyl salicylate and oxypropylated derivatives. 


\section{Conclusion}

These surfactants exhibit good surface including surface tension, moderate foaming, and good tolerance toward hard water, which are widely used in the field of surfactants industry. This situation focused our attention to find an economic low priced sources ( grape seed oil and Juagafa fat in an economic low priced sources for preparation of surface active compounds with high important applications in industrial field and decease the environmental pollution .

\section{References}

1. Levinson, M.I., Surfactant Sci. Ser. 142, 1 (2009).

2. Holmberg, K., (Ed.), Hanbook of Applied Surface and Colloid Chemistry, Vol. 1 John Wiley \& Sons Ltd (2002).

3. Lavergne, A., Yin Z., Aldo, P. Mlinier, V. and Jean-Marie, A., Synthesis and foaming properties of new anionic surfactants based on a renewabl building block: Sodium dodecyl isosorbide sulfates. J. Colloid Interface Sci. (Article in press) (doi:10.1016/j.jcis 2011.04,110) (2011) .

4. El-Dougdoug, W.I.A. and Ahmed, M.H.M., Preparation and surface active propertie of alkyl glucosides of fat Egyptian mangifera indica. J. Oil, Soap and Cosmetics, 50 (1), 25-26 (2001).

5. El-Dougdoug, W.I.A., Synthesis and surface active properties cationic surface active agents from crude rice bran. Grasas Y Aceites, 50 (5), 385-391 (1999).

6. El- Dougdoug, W.I.A., Hebash, K.A.H. and El-Sawy, A.A., Preparation and surface active properties of $\alpha$-Acyloxy succinic acid from malic acid and fatty acids of crude rice bran oil. Grasas Y Aceites, 51 (5), 340- 347 (2000).

7. El-Dougdoug,W.I.A. and Ahmed , M..M., Synthesis and surface active properties of Gawafa Fats based amphoteric surfactants. J. Oil Soap and Cosmetics, 53 (2), 6367 (2004).

8. Weil, J.K., Stirton, A.J. and Elizabeth A. Barr, J. Am. Oil Chem. Soc. 43, 157 (1966).

9. Chebicki, J., Tenside Detergents, 27, 413 (1990).

10. El-Sawy, A.A., Grasas y Aceites, 40, 382-384 (1989).

11. Micovic V.M. and Mihoilovic M.L.J., LAH in Organic Chemistry, Monograph Series, Vol 237, Serbian Academy of Science, 34-44 (1955).

12. El-Dougdoug, W.I.A., J. Dispersion Science and Technology, 31, 1298- 1042 (2010).

13. ASTM D1332-89, Standard text method for surface and interfacial tension of solutions of surface active agents (2001). 
14. Weil, J.K., Smith, F.D., Stirton, A.J. and Jr.Bistlin, R.G., Long chain alkane sulfonates and 1-hydroxy2-alkane sulfonates : Structure and property relations. $J$. Am. Oil Chem. Soc. 40 , 538-540 (1963).

15. Draves, C.Z. and Clarkes, R., J. Am. Dye Stuff Reporter, 20, 201 (1931).

16. Ross, J. and Miles, G.D., Apparatus for comparison of foaming soaps and detergent. Oil and Soap , 18, 99 (1941).

17. Takeshi, H., Bull. Chem. Soc. LB, 2236. (Japan) (1970).

18. El-Sukkary, M.M.A., El-Sawy, A.A. and El-Dib, F. Hungarian J. Industr. Chem. 15, 417 (1987).

19. Wilkes, B.G. and Wiekert, J.N. , Ind. Eng. Chem. 22, 1234 (1973).

20. Rosen, M.J., Surfactants and Interfacial Phenomena, $3^{\text {rd }}$ ed., Wiley New York (2004).

21. Huh, C. and Masan, S.G., A rigorous theory of ring tensiometry. Colloid \& Polymer Sci. 253, pp.566-580 (1975).

22. Eter, E.T., Richard, R. E. and Darid, A., Biodegradable surfactants derived from corn starch. J. Am. Oil Chem. Soc. 51,486- 494 (1974).

23. Rosen, M.J., Surfactants and Interfacial Phenomena. Wiley, New York p. 72 (1987).

24. El-Sawy, A.A., Mahmoud, A.A. and Shaker, N.O., Preparation and surface active agents properties of oxypropylated diol monoesters of fatty acids. J. Serb. Chem. Soc. 55, 395-399 (1990).

25. Ahmed, M.H.M., El-Dougdoug,W.I.A. and Sallay, P., Preparation and evaluation of surface properties of oxy propylated aralkylsulphate. Olaj, Szappan, Kozmetika, 51 (2), 77-80 (2002).

26. Chlebicki, J. and Kazimiera, S., Tenside \& Detergent, 17 (3), 133-134 (1980).

27. Falbe, J., Surfactants for Consumer. Chapter 4, Springer- Verlag, Heidelberg pp. 133-195 (1986).

28. Daniel Prats, Carmen López, Diana Vallejo, Pedro Varó and Víctor M. León, Effect of temperature on the biodegradation of linear alkylbenzene sulfonate and alcohol ethoxylate. J. Surf. and Deterg. 9, 69 (2006).

29. Gad, E.A.M., Azzam E.M.S., Aiad, I. and El-Azab, W.I.M., Molecular, surface, thermodynamic properties and biodegradability of nonionic surfactants based on caster oil. Tenside Surf. 46 (5), 272-278 (2009). 
تخليـق وتوصـيف الأكيـل سالسـيلات الأليفاتيـة العاليـه الأنيونيـهـ

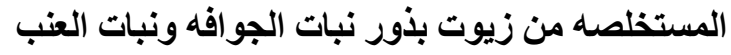

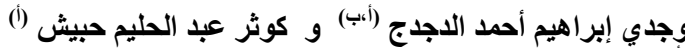

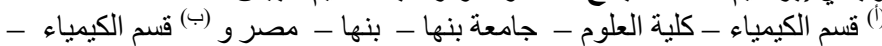

$$
\begin{aligned}
& \text { الكلية العالمية - جامعة أم القرى - مكة المكرمة - السعودية. }
\end{aligned}
$$

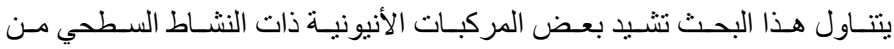

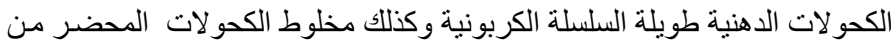

زيت العنب و الجو افة المحلية.

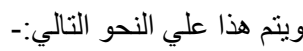

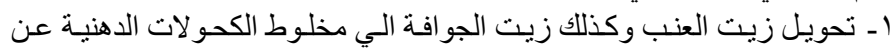

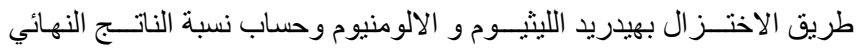

$$
\text { . (\% ^.) }
$$

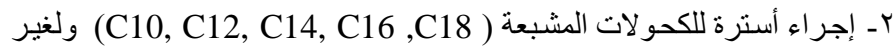

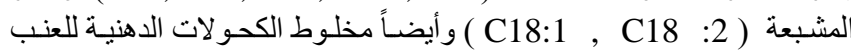

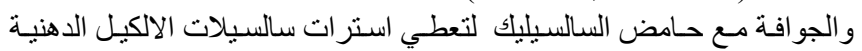

.( IIa-i )

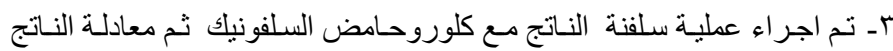

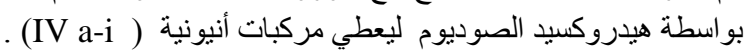

ع ـ لتحسين الخواص لتلك المركبات تم إضـافة أكسيد البروبيلين ثم سلفنة الناتج

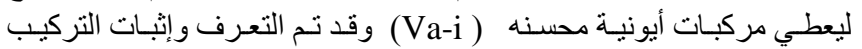

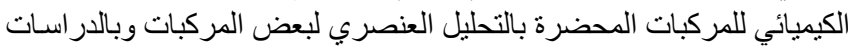

الطيفية للأشعة تحت الحمر اء والرنين النووي المغناطيسي.

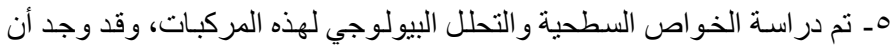

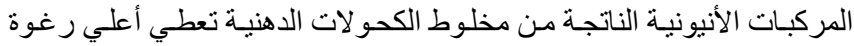

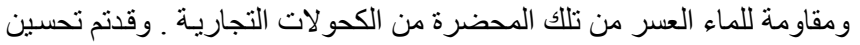

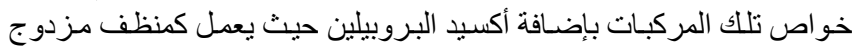

أنبوني و غير أنيوني ويمكن الاستفادة منه كمنظف قليل الرغوة في الغيل الغسالات

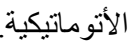

